\title{
Roepke Lecture in Economic Geography-Economic Geography, Manufacturing, and Ethical Action in the Anthropocene
}

\author{
2019, Forthcoming, in Economic Geography 95(1)
}

\section{Please cite but do not quote without authors' permission}

\author{
J. K. Gibson-Graham \\ Institute of Culture and Society \\ Western Sydney University \\ Penrith NSW 2751, Australia \\ K.Gibson@westernsydney.edu.au \\ Jenny Cameron \\ Center for Urban and Regional Studies \\ University of Newcastle \\ Callaghan NSW 2308, Australia \\ Jenny.Cameron@newcastle.edu.au
}

\section{Stephen Healy}

Institute of Culture and Society

Western Sydney University

Penrith NSW 2751, Australia

S.Healy@westernsydney.edu.au

\section{Joanne McNeill}

Institute of Culture and Society

Western Sydney University

Penrith NSW 2751, Australia

J.McNeill@westernsydney.edu.au

Key words:

applied geography, care, diverse economies, just sustainability, manufacturing

\section{Acknowledgments}

Katherine Gibson would like to thank James Murphy and nominators for the great honor of being invited to present the Annual Roepke Lecture at the 2018 Annual Meeting of the Association of American Geographers and Vicky Lawson for her thoughtful response. The lecture and subsequent coauthored article are based on collaborative research conducted with fellow members of the Community Economies Collective. We would like to acknowledge the ongoing influence of the late Julie Graham with whom we began seriously reflecting on economic diversity, even within the capitalist corporate sector. Sincere thanks must go to all research participants across Australian manufacturing who so readily engaged with us. We also thank the Australian Research Council for the financial support that has enabled our investigations. 


\begin{abstract}
In a world beset by the problems of climate change and growing socioeconomic inequality, industrial manufacturing has been implicated as a key driver. In this article we take seriously Roepke's call for geographic research to intervene in obvious problems and ask can manufacturing contribute to different pathways forward? We reflect on how studies have shifted from positioning manufacturing as a matter of fact (with an emphasis on exposing the exploitative operations of capitalist industrial restructuring) to a matter of concern (especially in advanced economies experiencing the apparent loss of manufacturing). Our intervention is to position manufacturing for the Anthropocene as a matter of care. To do this we pull together feminist insights into care as an embodied entanglement of ethical doings and material transformation, and applied insights into the building of just sustainabilities in place. This thinking frames our discussion of four diverse manufacturing enterprises in Australia (two capitalist firms, a co-operative, and a social enterprise). We make the case for economic geography to attend to ethical economic actions that make other worlds possible.
\end{abstract}

\title{
Roepke Lecture in Economic Geography_Economic Geography, Manufacturing, and Ethical Action in the Anthropocene
}

In his 1977 article “Applied Geography: Should We, Must We, Can We?” Roepke urges geographers to "study obvious problems and to be bold enough to advocate the solutions that their research indicates would be useful." He prefaces this exhortation with the comment that "there is no need to search for problems - many already exist and are recognized by everyone" (Roepke 1977, 481-82). These comments, by the geographer in whose memory the Roepke lectures are given, bear directly on the agenda of the research we present here. The obvious problem we are tackling concerns how we make things in a world beset by climate change and growing socioeconomic inequality. Making thingsmanufacturing - lies at the heart of both these problems. Manufacturing industries fueled by petro-chemicals have driven rampant consumerism, producing detrimental environmental impacts; automation and off-shoring of production have cut off employment pathways for many in older industrialized countries, exacerbating income inequalities. But can the way we make things be part of a solution?

Roepke's article provides a summary of a symposium, Applications of Geographic Research held at Michigan State University in the same year. ${ }^{1}$ One of the geographers present was Pattison who proposes "that the discipline of geography is perhaps entering a new phase. The first phase, involving much of the early descriptive work, was one simply of presentation; the second, involving quantitative research and model building, was one of investigation; now we may be moving into a third phase, that of intervention" (cited in Roepke 1977, 482). Of course, at that time a younger group of geographers were questioning

\footnotetext{
${ }^{1}$ The 1977 symposium was followed by special sessions on applied geography at the 1978 Annual Meetings of the Association of American Geographers held in New Orleans. There is some accidental symmetry in the fact that the 2018 Roepke lecture was presented also in New Orleans and that the presenter, Katherine Gibson, had attended the 1978 New Orleans AAG meetings (her first) as a graduate student.
} 
whose interests applied geography was serving. In the wake of Harvey's (1973) Social Justice and the City, radical geographers began to critique the status quo interventions that were the bread and butter of applied geography, and the disengaged objectivity and perceived impartiality of geography. They argued for system-changing interventions that would address problems of uneven development, exploitation, and inequality. In the first half of this article, we briefly discuss how the study of manufacturing has changed since this commitment to geographic research as a form of radical intervention was first voiced. We discuss how, since the global financial crisis (GFC), the study of manufacturing has shifted from being a matter of fact to a matter of concern, to use Latour's terms (2004). We then turn to today's obvious problem and situate manufacturing with respect to the Anthropocene-as contributor to the Great Acceleration (Steffen et al. 2015) and as a key player in the critical zone (again, a term from Latour 2014). In terms of our intervention, we highlight how manufacturing might be approached as a matter of care by drawing on recent feminist scholarship. We then discuss our ongoing research in Australia, which is exploring manufacturing as a potential site of transformation. ${ }^{2}$ Here we feature manufacturers that are making the stuff that helps us to survive well, using the concept of "just sustainability" as coined by Agyeman and colleagues to identify how these manufacturers are ensuring "a better quality of life for all, now and into the future, in a just and equitable manner, whilst living within the limits of supporting ecosystems" (Agyeman, Bullard, and Evans 2003, 5). In the conclusion, we propose that research interventions in economic geography take up the challenge of caring for new cultures of manufacturing for the Anthropocene.

\section{Manufacturing as a Matter of Fact}

Over the past century, manufacturing activity has been a major focus of study in industrial geography, once a key subfield of economic geography. If we take Pattison's characterization of the phases of the discipline (as cited in Roepke 1977, 482), early geographies focused on describing where industrial activity was located and presenting the different geographies of specific manufacturing sectors. A second phase involved quantitative research that applied models of least cost location to investigate and explain the spatial distribution of manufacturing activity. In the late 1970s, the internationalization of production capital was beginning to undermine the robustness of these models of national industrial location. Economic geography was challenged to explain industrial restructuring and come up with new theories of location. This was the time when postwar manufacturing growth was faltering in older industrialized economies, and economic geographers were turning their attention to the relocation of manufacturing plants and jobs to low wage areas offshore or to nonindustrial low-wage regions within the national polity. Here the seeds were being sown for a narrative of manufacturing decline in countries like Australia, Canada, the UK, and the US - where support for national industrial policy was also being undermined by the ascendency of neoliberal governance models.

\footnotetext{
${ }^{2}$ Australian Research Council Discovery Project 2016-2019 "Reconfiguring the Enterprise: Shifting Manufacturing Culture in Australia" (DP160101674).
} 
Economic geographers contributed with what was at first seen as a radical interventionist attempt to apply Marxist theories of capital accumulation married with long wave theories of technical revolution to the changing sectoral dynamics of production. ${ }^{3}$ As this approach became increasingly accepted, there was a shift to studies and theorizations of the spatial dynamics of structural change, for example, Massey and Meegan (1982) The Anatomy of Job Loss, Massey (1984) Spatial Divisions of Labour, and Bluestone and Harrison (1982) The Deindustrialization of America: Plant Closings, Community Abandonment and the Dismantling of Basic Industry. Here the emphasis was on regional decline and what could be done about it. The other side of the coin was the emerging focus on new areas of manufacturing growth in greenfield sites at some distance from deindustrializing regions, and new growth areas in the global economy (e.g., Scott's 1987 work on the semiconductor industry). The theorization of industrial restructuring settled on the analysis of regimes of accumulation, and for those interested in labor, the focus was on the implications for workers and ways of organizing within the regime of post-Fordism (e.g., Herod 2001). This political economy approach laid the foundation for what was to follow, and, by the 1990s, had become more or less mainstream. Study after study identified the latest business strategies and the locational implications for manufacturing enterprises and investment capital on a global stage. Each new edition of Dicken's (2015) Global Shift: Mapping the Contours of the Changing World Economy from 1992 to 2015 tracks and traces these changing facets of global production. We could represent this political economy approach as positioning manufacturing as a matter of fact (to use Latour's 2004 language) aimed at revealing the underlying dynamics of capitalist accumulation and the violence afforded by new sites of exploitation and profitability.

For researchers interested in contributing to a politics of change, there were limits to this form of intervention. Studies demonstrated time and again how capitalism was becoming globally entrenched and how the options for transformation were restricted. ${ }^{4}$ Industrial restructuring was represented in such a way as to instate a totalizing, all powerful, capitalism. Gibson-Graham $(1996,35)$ names these representational strategies "capitalocentric," borrowing from poststructuralism's conception of logocentrism and feminism's phallogocentrism. One of the effects of normalizing capitalist economic relations is, GibsonGraham argues, to sideline and subordinate other noncapitalist forms of economy and other more-than-capitalist economic dynamics. Economic geography, with its emphasis on

\footnotetext{
${ }^{3}$ Beginning with graduate study at Clark University, the first author spent many years with others theorizing the relationship between falling rates of profit in manufacturing sectors and structural reconfiguring of the conditions of capital accumulation (e.g., Gibson and Horvath 1983a; Gibson et al. 1984; Graham et al. 1988; Gibson, Graham, and Shakow 1989). This updating of classical Marxist research was an attempt to understand the variations within capitalism - this author's initial foray into the terrain of economic difference, albeit the difference between competitive, monopoly and global capitalist activity at the level of manufacturing sectors (Gibson 1980; Gibson and Horvath 1983b).

${ }^{4}$ A pivotal moment for the first author occurred during an address given by the Australian trade union leader and class warrior Laurie Carmichael in the mid-1980s when he was putting the case for workers to join in and get our bit of the World Car for Australia. What was confronting was that the critical Marxist analysis we shared did not contribute any kind of strategy for transformation - the pragmatic approach was to get a part of the pie for the members and not to concede union power.
} 
revealing facts associated with the machinations of global capitalism, was helping to shore up capitalist hegemony. Other potential research agendas were foreclosed, including research on noncapitalist economic practices and organizations that had something to offer in terms of economic experimentation and even economic transformation (Gibson-Graham 2006; Gibson-Graham 2008; Gibson-Graham, Cameron and Healy 2013). These insights provided the basis for what was to become the diverse economies research program. ${ }^{5}$ Researchers in this program pursued pioneering action-oriented interventions with communities that were being bypassed by capital investment and jobs growth or negatively impacted by neoliberal resource management (e.g., Community Economies Collective 2001; Cameron and Gibson 2005; Healy 2015; St. Martin 2001; Gibson, Cahill, and McKay 2010). ${ }^{6}$ In this article, our action-oriented intervention in Australia is focused on manufacturing activities located in Sydney and regional New South Wales (NSW).

\section{Manufacturing as a Matter of Concern}

The 1980s was perhaps the heyday of research in economic geography on manufacturing. However, if we fast forward to the last decade and the period since the GFC of 2008, there has been a resurgence of interest in the manufacturing sector-if not in economic geography, then at least more generally. We propose that in this period, manufacturing features as a matter of concern (Latour 2004), certainly in those nations where manufacturing industry policy had been largely abandoned. According to Latour, a focus on matters of concern rather than matters of fact means a shift away from criticism and debunking, away from revealing the inner workings of structures, and away from incorporating new evidence into the same narrative. In his view, the dominant focus on matters of fact has involved conspiratorial filters that have had the effect of subtracting diversity and possibility from the world. To take up matters of concern, Latour argues, means directing attention toward a stubbornly empiricist approach that seeks to add meaning to the world - an approach that protects and cares in some way. ${ }^{7}$

According to Vanchan, Bryson, and Clark (2015), editors of Handbook of

Manufacturing Industries in the World Economy, manufacturing has become a matter of national concern since the GFC. In this period, there has been a much greater appreciation, at least in policy circles, of manufacturing and the role that it plays in a balanced economy. Along with this appreciation has come the concern to maintain and support manufacturing. They write, "[s]ince the 'Great Recession' of 2008, the voices expressing a conventional

\footnotetext{
${ }^{5} \mathrm{~A}$ research program that, some twenty years after its inauguration, has been recognized as a subfield of human geography, with the forthcoming publication of the Handbook of Diverse Economies edited by J. K. GibsonGraham and K. Dombroski.

${ }^{6}$ While staying within the broad fold of economic geography, this interventionist research operated at some distance from what had become mainstream industrial geography.

${ }^{7}$ Latour $(2004,232)$ writes, Can we devise another powerful descriptive tool that deals this time with matters of concern and whose import then will no longer be to debunk but to protect and to care, as Donna Haraway would put it? Is it really possible to transform the critical urge in the ethos of someone who adds reality to matters of fact and not subtract reality? To put it another way, what's the difference between deconstruction and constructivism?
} 
wisdom that advanced economies can sustain economic shocks without a strong production base have all but been silenced" (Clark, Bryson, and Vanchan 2015, 492). The volume of policy-based research reports that have been published since 2008 in countries, such as Australia, Canada, the UK, and the US, is evidence of how manufacturing now features as a matter of policy concern. The titles of these reports are revealing, for example, Why Does Manufacturing Matter? Which Manufacturing Matters? A Policy Framework (Helper, Krueger, and Wial 2012); A Landscape for the Future of High Value Manufacturing in the UK (Technology Strategy Board 2012); Strengthening Canada's Manufacturing Sector (Industry Canada 2015); and Advanced Manufacturing: A Roadmap for Unlocking Future Growth Opportunities for Australia (Commonwealth Scientific and Industrial Research Organisation [CSIRO] 2016). These types of reports highlight some of the important economic features of manufacturing, including its innovation intensity (higher than any other sector); its export orientation, with 60 percent of what is traded being manufactured; the unique supply chain that lies behind every manufactured good; and that it is the source of high-quality jobs (Stanford and Swann 2017). In line with our interest in the link between manufacturing and environmental sustainability, one report highlights the crucial role that manufacturing plays in the clean economy (Helper, Krueger, and Wial 2012).

While policy concern for manufacturing is high, Vanchan, Bryson, and Clark (2015) note that this has not been mirrored in academic circles. Instead "[m] uch of the academic debate and literature has revolved around understanding the new knowledge-based economy and the service sector in general, and there has been a much more limited focus on manufacturing" (Vanchan, Bryson, and Clark 2015, 5). When manufacturing has been the focus, attention has remained on the factors bearing upon manufacturing decline. The narrative of manufacturing decline that began with off-shoring of production has been strengthened by analyses of financialization that highlight how the viability of manufacturing activities within larger corporate entities has been undermined by asset stripping and subsequent layoffs (Christopherson 2015). One of the implications of this focus is that academic understanding "has not kept pace" with the transformations that are taking place within manufacturing (Vanchan, Bryson, and Clark 2015, 5). For example, production is being reshored as the demand for bespoke and quality goods has grown, and labor costs have become less important (e.g., CSIRO 2016, v). There has also been a marked change in relations between producers and customers as the distinction between manufacturing and service activities has become blurred (Goennemman 2016).

Just as academic understanding has not kept pace with the changes, so too the public perception is out of step. Vanchan, Bryson, and Clark $(2015,5)$ note that

The manufacturing stigma is not easily obliterated from the minds of those who consider manufacturing employment as low waged, labor intensive, repetitive, outdated and temporary; making it less attractive to young workers and entrepreneurs than service employment.

The stigma of manufacturing as a dead end sits paradoxically alongside the policy concern to build more balanced national economies that include manufacturing activity. This has led to debates in older industrial economies in which questions, such as the following, are being 
asked: Do we need a manufacturing sector? What type of manufacturing do we want? What makes manufacturing viable? How should policy assist the manufacturing sector?

An air of anxiety permeates these debates about the future of manufacturing. It is worth noting that anxiety, in the Lacanian tradition, is a kind of diffuse bodily affect - one that can, and does, overwhelm the subject but one that is not without an object (Copjec 2006). Copjec (2006), interestingly, uses Charlie Chaplin's character in the movie Modern Times (caught up in the gears, unable to keep up) as the illustration of anxiety. We can see this anxious concern for the future of manufacturing fueling the attachment to technoscientific solutions (such as robotics, nano-science, artificial intelligence, algorithms) as a means for revitalizing industry through a focus on innovation. Yet these concerns to keep up with technological developments appear to sidestep more fundamental problems facing manufacturing.

\section{Manufacturing and the Critical Zone: The Obvious Problem}

As Roepke points out in his 1977 article, there is no need to search for obvious problems, they find us - and they call for a bold approach to advocating solutions. ${ }^{8}$ In terms of today's obvious problems, we face perhaps the biggest set imaginable - the interconnected problems of increased climate instability and change, and rising inequality. It is ironic that they are the product of our efforts at creating a world of comfort and convenience. Manufacturing, as we have known it, is at the center of these problems and is deeply problematic on two fronts.

On the first front, the science is now in. A stratigraphic signal has been identified that sets off a new geological era from the Holocene. The horizon occurs around the year 1950. It is marked by "the appearance of manufactured materials in sediments including plastics, aluminium and concrete [and] coincides with global spikes in fallout radionuclides and particulates from fossil fuel consumption" (Waters et al. 2016, 138, emphasis added). Plastic, aluminium, concrete, and fuel particulates are the manufactured materials that are so familiar they are unremarkable. They are what we drink from, what we live in, what we move with. This period from the 1950s has been called the Great Acceleration (echoing Polanyi's The Great Transformation, as noted by Steffen et al. 2015). It is characterized by "a prominent rise in economic activity and resource consumption" (Waters et al. 2016, 140), and humaninduced global warming. In all the agitated debate about what we should call this geological era-contentiously named the Anthropocene, or even more contentiously, the Capitalocene, or the Plantationocene-perhaps we should add the postwar manufacturing-o-cene.

Rather than critically naming and shaming, some have thought of the Anthropocene in other ways. Haraway describes it as "more a boundary event than an epoch" $(2015,160)$. She goes on to say that

The Anthropocene marks severe discontinuities; what comes after will not be like what came before. I think our job is to make the Anthropocene as short/thin as possible and

\footnotetext{
${ }^{8}$ Given all we have learned through the twentieth century about the hubris of solutions, we prefer to advocate with less modernist certainty for a bold approach to advocating pathways forward.
} 
to cultivate with each other in every way imaginable epochs to come that can replenish refuge.

Latour draws our attention to what he calls the critical zone (2014). The critical zone is "that spot on the envelope of the biosphere" (Latour 2014, 4) where living organisms and the earth's rocky surface interact to create the habitats that "determine the availability of lifesustaining resources" (National Research Council 2001, 2). It is a living, breathing, constantly evolving boundary layer where rock, soil, water, air, and living organisms interact. These complex interactions regulate the natural habitat and determine the availability of lifesustaining resources, including our food production and water quality. Latour (2014) suggests that it is in the critical zone where some of the most pressing problems of our age can be parsed,and where the actions of humans can be radically reshaped to compose our common world differently. Indeed, he writes of how he is attracted to the idea of the critical zone over the Anthropocene as "the notion of the critical zone is much less paralysing for politics than that of the Anthropocene" (Latour 2014, 4).

One of the potentials of this notion is the way the critical zone reframes the place of humans. It displaces the idea that human and physical geographies are layered one upon the other, with the top human layer having its own dynamism played out upon a relatively stable physical layer. As Latour suggests "[i]t is precisely this idea of layered dimensions that seems to disappear and that gives critical zone its originality" (2014, 5, emphasis in original).

Instead human and physical geographies are intermingled; for example,

To trace the nitrogen cycle might bring you just as quickly to enter a (human made) factory as following (nature made) calcium release from rock would lead you to study some regulations imposed by forest engineers who had read new textbooks on soil management.

As this quote highlights, manufacturing is a key player in the critical zone where life and nonlife touch and interact to produce the conditions of existence for more and different life. The bits of plastic and concrete and aluminium - these artifacts of manufacturing production - that have insinuated themselves into the sedimentary record are traces of an elaborate assemblage of material and social relationships that has burgeoned exponentially during the Great Acceleration. The ramping up of manufacturing since the 1950s has contributed to massive wealth generation, but it has also contributed to global warming and planetary climate change. Those convened by manufacturing as a matter of concern need to take into account not just technoscientific solutions but the ecologies, species, and atmospheres whose healthy survival is threatened by manufacturing as we have known it. For us, it is concerning that these life-sustaining elements of the critical zone feature so little in debates about manufacturing. ${ }^{9}$

\footnotetext{
${ }^{9}$ Indeed, the conclusion to the Handbook of Manufacturing Industries in the World Economy positions technologically advanced manufacturing as the next industrial revolution that will produce "regeneration economies" (Clark, Bryson, and Vanchan 2015, 491). Yet there is only one chapter that explicitly addresses the importance of innovation that might be connected to climate change, and this is the chapter on "Energy and Manufacturing." The index to the book contains no entries for climate change, environment (apart from Environmental Protection Authority), or sustainability.
} 
Here we have the first major issue at stake when thinking about the future of manufacturing - is it to continue to contribute to planetary climate instability and environmental degradation, or not? Can manufacturing and the kind of consumption practices it fosters be part of a solution to global warming?

A second major issue at stake is the role of manufacturing in the wider polity. The period of the Great Acceleration saw both decades of wealth redistribution within some nation-states driven by national policies informed by socialist and social democratic values, and more recently decades of wealth polarization underpinned by what some call neoliberal globalization. Researchers, such as Thomas Picketty, have demonstrated that in countries such as Australia, Canada, the UK, and the US there was a marked shift from declining levels of income inequality in the 1950s through the 1980s, to increasing levels of inequality from the end of the 1980s (Cassidy 2014). There is no doubt that in the period following the Second World War, manufacturing played a pivotal role in helping to address income inequality. Through employment in manufacturing, the economically marginalized were incorporated into the economy, and a powerful union movement pushed for strong wage growth. Certainly, there was a downside to the complexion of economic inclusion through manufacturing. In Australia, for example, manufacturing growth was built upon a White Australia policy, and other than migrant women (many of who were employed in the clothing, footwear, and textile sector), most women were excluded. We come then to the second issue at stake when thinking about manufacturing as a matter of concern-who is to be included and who is excluded in this future? Is manufacturing to play a role in reducing the growing disparity in wealth distribution? Can manufacturing enterprise address the challenge of producing a more equal society?

These two sets of issues are encapsulated in the catchphrase just sustainability coined by Agyeman, Bullard, and Evans (2003). This phrase neatly connects social concerns around inequality and inclusiveness with environmental concerns around planetary ecological health. A just sustainability involves " $t]$ he need to ensure a better quality of life for all, now and into the future, in a just and equitable manner, whilst living within the limits of supporting ecosystems" (Agyeman, Bullard, and Evans 2003, 5). ${ }^{10}$ The question is, can manufacturing contribute to strengthening just sustainability in the current context? Our answer is, if it is to do so, manufacturing must be reconfigured not only as a matter of concern but as a matter of care.

\section{Manufacturing as a Matter of Care}

What then does it do to add care for manufacturing to concern for manufacturing? Puig de la Bellacasa argues in her 2017 book Matters of Care: Speculative Ethics in More

\footnotetext{
${ }^{10}$ This conviction of the need to progressively enact a more inclusive and caring politics, rather than presume one, grew from a critique of the environmental movement's early blindness to intergenerational inequities and injustices - the equity deficit that still, Agyeman argues, "pervades most 'green' and environmental sustainability theory" $(2013,124)$. Environmental concerns might be posed as universal but, Agyeman warns, we risk replicating existing inequalities if we do not attend to whose experiences, desires, or cultural values are accounted for when environmental concerns are addressed.
} 
Than Human Worlds that an ethics of care involves a different dispositional inflection, one that is much more embodied and entangled with the haptic than a well-intentioned, but rather cerebral attitude of being concerned. Care involves seeing with our fingers and a kind of acknowledgment that when we care about things - the layout of the manufacturing floor, microbiomes, babies - we touch and are touched by them. Care entails active experimental doings that involve negotiating interdependence and constraint in place, deciding, choosing, privileging and taking responsibility, and enacting an ethos. All these actions must be pieced together outside of given codes of conduct. By addressing manufacturing in this way as a matter of care, we are heeding Lawson's call to link "political-economic and emotional geographies" $(2007,6)$, refusing to banish from economic research questions of care.

Puig de la Bellacasa takes up the expansive definition originally coined by Tronto and Fisher $(1990,40)$ who viewed care as

a species activity that includes everything we do to maintain, continue, and 'repair' our world, so that we can live in it as well as possible. That world includes our bodies, our selves, and our environments, all of which we seek to interweave in a complex lifesustaining web.

But in her book Puig de la Bellacasa decenters the human focus of this definition broadening the concept to engage with more-than-human worlds and agencies (2017). It is here in the more-than-human life-sustaining web where manufacturing as a matter of care is located. Manufacturing - from manus the Latin for hands and facere, to make-means hands making. ${ }^{11}$ As with care, manufacturing involves a material entanglement with things that sustain life and with others (ecologies/people) in need of care.

Today we could be forgiven for thinking that the hand and touch play little role in the process of making. The power of a simple narrative initiated in the nineteenth century is to blame. In Capital Vol. 1 Marx (1992) made much of the distinction between manu-facture and machino-facture. He saw manu-facture, which he associated with craft production, being replaced by machino-facture, which he associated with modern industry. Today current theorists of the workplace point to the shift from machino-facture to robo-facture, and perhaps soon to be replaced by algor(ithm)-facture. This unilinear trajectory still has currency, contributing to anxiety and suggesting further marginalization, as though it were a fait accompli, of the role of the hand with its very human capacities for hand-eye-brainaesthetic coordination in making. A "current 'making' zeitgeist" (Beverland et al. 2015, 175) is, however, promoting renewed interest in the materiality of making and the association between manu-facture, art, craft, design, creativity, and innovation. This new maker revolution flies in the face of a perceived marginalization of the hand in the process of industrial production.

Certainly, if we want to care for manufacturing in the critical zone and for its potential to promote just sustainability, then we need to open up to possibilities for the careful touching of materials, hands, machines, products and waste, and for ethical interactions between craft, design, engineering, mass, and bespoke production. As geographers Carr and Gibson put it,

\footnotetext{
${ }^{11}$ It is worth noting that the stem word for facture, factum, is also the origin of fact—something we also make.
} 
we need to attend to "how humans manipulate materials, compose objects and construct economies and societies around material things - as well as how this might be done differently" (2016, 300-301, emphasis added). Doing manufacturing differently will crucially involve attention to the characteristics of place and to geographic constraints and enablers.

In the highly internationalized economy of Australia, there was an air of anxiety about the future of a national manufacturing sector around the closure in 2017 of the last car assembly plants. It was in this context that we sought out manufacturing enterprises that are doing things differently by going some way toward achieving just sustainability. We have conducted case study research with ten different manufacturing enterprises, including capitalist companies, cooperatives, and social enterprises with operations in metropolitan and regional NSW. We have spent time observing manufacturing on the shop floor and interviewing more than sixty people from various positions in each enterprise (including some from overseas branches). We have then reported back our findings in the context of onsite workshops with interviewees. Our objective has been to engage in a research conversation in which the actions of manufacturers are viewed through the lens of care for people and the planet. In line with our interest in the performativity of research, our aim is to contribute to a new vision of manufacturing in Australia as a site of problem solving for planetary challenges. ${ }^{12}$

\section{Manufacturers Caring for Just Sustainability in Australia}

The four manufacturing enterprises we discuss here are Interface Inc., a US-based publicly listed company that is the world-leading maker of carpet tiles for offices and institutions, and has a manufacturing plant on the outskirts of Sydney; Varley Group, a family-owned private company founded in Newcastle, NSW, in 1886 that is one of Australia's major engineering firms producing specialist vehicles, such as ambulances, breast screen vans, fire trucks, rescue vehicles and electric vehicles as well as equipment for the defense and aerospace sectors; Norco, a 123-year-old farmer-owned cooperative in Northern NSW that consists of 200 dairy farmers who form the producers cooperative, 32 coop owned rural supply stores, and three manufacturing plants producing packaged fresh milk products and ice cream, as well as being a cheese brand owner; and Soft Landing, a national social enterprise operating across the Australian Capital Territory, New South Wales, Victoria, and Western Australia that recycles mattresses that otherwise get dumped into landfills.

Each of these enterprises transforms materials through touch and care into something that will contribute to human well-being. For Interface, carpet provides comfort and aesthetic pleasure, as a senior executive from Europe explains "carpet plays a very important role for human wellbeing being in a work environment or a living environment. It's about design ... it influences how you feel at work, it's about acoustics, it's about comfort." For Varley, engineered products are based on durability and safety: "giving the customer the best we can, because we know they're going to be living with that product for 15, 20 years. The last we

\footnotetext{
${ }^{12}$ A subsequent phase of the research will bring representatives of each enterprise together to share insights about enablers and challenges to caring for just sustainability. The aim will be to prepare for a public forum to be held in 2019 on New Cultures of Manufacturing in Australia.
} 
want is someone saying, who built that, it doesn't work, or that it broke down" (General Manager, Defense and Aerospace). For Norco, the focus is on fresh milk and milk-based products: "[i]t's about provenance and the quality, and price comes in at number three" (General Manager, Sales and Marketing). For Soft Landing, it is about ensuring material recoverability of a consumer item that normally ends up as landfill: "[w]e saw that there's probably one and a half million mattresses a year being thrown out in Australia ... We know that currently those mattresses are going into landfill, or 80 per cent of them are ... so let's see if we can reduce that" (Executive Officer).

Alongside the pride and care that these manufacturers have for their product, there is also a commitment to just sustainability in place and for the planet. They demonstrate how manufacturers "manipulate materials, compose objects and construct economies and societies around material things" (to requote Carr and Gibson 2016, 301) in ways that are based on care for the environment and care for socioeconomic well-being. In what follows, we overview how the four manufacturers are addressing the environmental dimensions of just sustainability, and then we explore one of these dimensions in more detail with the example of Interface. We then overview the socioeconomic dimensions and explore one of these dimensions through the example of Soft Landing.

\section{Environmental Dimensions of Just Sustainability}

Care for the environment is expressed firstly by eliminating waste in the production process, as particularly demonstrated by Interface, Varley, and Norco. Within economic geography, lean has been chiefly associated with just-in-time supply chain management (e.g., Schoenberger 2000). More broadly, lean is about eliminating waste in transport, inventory, motion, overproduction, and defects (Cherrafi et al. 2016). As one tiny example, at Varley bolts, nuts, and washers come in kits from the supplier already sorted for the assembly process. As one manager explains, "I don't have to go through boxes and try to segregate it myself or count how many I need. It's already come pre-packaged directly to the assembly cell" (General Manager, Defence and Aerospace). Production costs are reduced, and there is less waste of materials because there is no excess production. Interface's Vice President Operations, Asia Pacific observes, "If you remove the waste, you improve your sustainability ... So sustainability is not just about using green power and using bio-based material or recycled material, it starts with making sure that you just use what you need" (emphasis added). This observation is consistent with recent studies that have similarly observed the connection between lean and green (e.g., Chiarini 2014; Inman and Green 2018). A second way that care for the environment is expressed is by repositioning waste as a resource. This ranges from the simple practice of recycling broken plastic milk crates so they can be remanufactured into other plastic-based products, such as planter pots (in the case of Norco), to an enterprise that is entirely based on the end-of-life recycling of mattress components (in the case of Soft Landing). Here Soft Landing's approach is instructive. They have developed processes for the careful undoing of innerspring mattresses. The steel is compacted and melted down for reuse; the wood is shredded for garden mulch; and the fabric is manufactured into products such as removalist blankets, and weed suppression and soil 
stabilization matting. Currently, some 15 to 20 percent of the mattress goes to landfill, but the goal is for the entire mattress to be recycled. At the time of writing, Soft Landing was finalizing the intellectual property for a new product, developed in collaboration with materials scientists from the University of New South Wales that would use this final portion of the deconstructed mattress.

Manufacturers are also pushing at the limits of what materials can do to address sustainability. Interface, a world leader in materials innovation, has worked on decarbonizing its product, ever since 1994 when the founder, Ray Anderson, initiated a radical transformation of the culture of the company. Up till this point Interface had been a "profitonly business with little consideration of [its] effect on the planet beyond that required for legal and regulatory compliance" (Nelson 2009, 22). After his sustainability epiphany (Nelson 2009) prompted by reading Paul Hawken's (2010) The Ecology of Commerce, Anderson committed himself and the company to building a restorative economy and rethinking the nature of business. Interface abandoned the linear take-make-waste model of production and redesigned production along circular economy lines. As Anderson explained to his staff in 1997, the intention was "to spend the rest of our days harvesting yesteryear's carpets and other petrochemically derived products, and recycling them into new materials" (cited in Woo 2011). In 2006, the company formalized Anderson's vision into a plan called Mission Zero ${ }^{\circledR}$ aiming to "eliminate any negative impact Interface has on the environment by 2020" (Nelson 2009, 24). The company is on track to achieve this aim and has now moved onto a second agenda, Climate Take Back ${ }^{\mathrm{TM}}$.

At Interface, care for the environment and sustainability now takes place at all stages of the production process - product design, emissions, energy use, recycling and reuse, and transportation. It is in the materials science laboratories where the challenge of touching materials and caring in new ways has been pioneered. The task of reusing petroleum-based nylon fiber was an initial hurdle, as was the task of separating the carpet tile backing from the carpet face so that each material could be reused separately (Nelson 2009). In more recent years, it has been the development of bio-based synthetic yarn that has been the focus of innovation. After experimenting with corn-based yarn, Interface switched to castor bean bioyarn, which is recyclable, is not a food stock, and is grown on the edges of deserts, helping to revegetate and reduce carbon (Interface 2012). The result of these endeavors is that Interface now employs a diverse range of production inputs:

Ray talked about using materials that have already been extracted and used already, reusing them to make new products ... beyond that is being able to not only reuse our materials to make new product, but also use waste material to make new products, as well as bio-based material to make new products. So, it gives us the flexibility of doing products either from bio-based materials, from recycled materials that have nothing to do with carpet, or from carpet material. (CEO, Australia and Pacific)

This journey toward sustainable production may initially cost the company, but the intention to care for the planet drives innovation, which ultimately changes the economic equation. As the Sustainability and Lean Manager explains, "You don't take carpet back if it's costing you an arm and a leg... Ray Anderson didn't really care about that when he said it at the start. He 
said, you better make it cost effective. So that's where engineering comes in, innovation, new technologies. That's where that all comes in."

\section{Social Justice Dimensions of Just Sustainability}

Care for socioeconomic well-being, or the just side of just sustainability, is practiced through remuneration rates. Employees of the four manufacturers are paid at or above award wages. In Australia, award (or minimum) wage rates and job conditions are legislated for particular sectors of industry. Unions play a role at the individual business level in negotiating enterprise bargaining agreements that pay above award wages. Well-being and justice are provided with opportunities for career progression for employees. There is an emphasis on providing training so that employees can develop their skills and progress into other roles. For example, Interface's Vice President Operations, Asia-Pacific explained, "we're quite keen to have people who are looking for an opportunity to grow and grow up. We will offer them the training to grow up". Another feature is the relationship with casual employees. In these manufacturers there are both core permanent full-time workers and casuals who are employed on a temporary basis according to production demands. On the north coast of NSW where Norco is one of the few major employers, factory staff commented on the strong competition when casual openings become available. The cooperative tries to make sure that the casuals are provided with enough hours of employment so that they "hang around and won't go away" as the casual workforce often operates as the recruitment ground for permanent workers. At the same time one factory manager noted that "some of the casuals want to be casual ... they don't necessarily want a five-day job, they want to come and do some fill-in work ... They're still committed to the business, but they don't necessarily want to have a full-time position."

Traditionally in Australia manufacturing employment has been open to those at a distance from the labor market. For decades, migrants, especially those with limited English language skills and education, have accessed employment through the manufacturing sector. This pattern was evident in all our visits to factory floors. But across Australia there are some groups who find it particularly hard to find employment. Here social enterprises such as Soft Landing play a crucial role. As the Executive Officer states,

We aim to assist people experiencing disadvantage to develop social and economic livelihoods for themselves ... [we] have a target group that particularly includes Aboriginal people experiencing disadvantage, but people experiencing homelessness, ex-offenders, early school leavers, those sort of things, are our target.

Training and support in the workplace and beyond is key to this mission, as one supervisor explained:

We put this kind of effort into their education and training because a lot of them finished in Year 9 at school ... We tailor their training, too, because we understand that a lot of them don't have a high level of literacy and numeracy skills. So it's tailored to their needs where they're going to learn something out of it ... We try to put them in touch with other services that can help them find a place to live. 
As a social enterprise, Soft Landing is explicitly focused on providing opportunities for groups experiencing disadvantage. Here there are opportunities for social enterprises to partner with for-profit firms. Internationally, Interface is working with social enterprises to achieve its goals of minimizing environmental harms. In Europe, the collection and cleaning of used carpet tiles that will be reused is in the hands of a partner social enterprise, and in the Philippines and Cameroon Interface collaborates with a nongovernmental organization that works with local villagers to collect abandoned nylon fishing nets that are fed into the materials reuse stream. Concerns for equity are not limited to social enterprises. For example, Varley Group has strategies in place for providing employment pathways for groups that can find it difficult to access jobs. This has led to employment for ex-prisoners, Aboriginal people, and those experiencing mental health issues.

In their different ways, each of the manufacturers is taking responsibility for their role as an actor in the planetary critical zone and in the emplaced communities in which they operate - more than simply expressing a concern about issues of socioeconomic justice and environmental sustainability they are acting on their concerns and practicing care for people and planet.

\section{Business Viability and Care for Manufacturing}

While we can identify what each of the enterprises discussed in this article is doing to care for just sustainability in place, we are also interested in how they are able to do so in a business world of global competition and national cost constraints. There is little apparent leeway to attend to matters of care that do not also advance business viability. As a senior executive from Interface commented, 'I always say it doesn't help anyone if we're green but broke. So it's got to stack up financially as well." What our research has shed light on is the way that business viability is being redefined through ethical doing.

The care commitments enacted by our enterprises are definitely experimental and ongoing. We have been able to capture glimpses of the complexity of these enactments by gathering small stories that demonstrate how, in the face of economic pressures to conform to a business as usual imperative, an explicit caring response has prompted doing things differently. What we can learn from these small stories is how ethical action might transform business culture and lead to a new way of doing justly sustainable manufacturing.

\section{National Production in the Face of Offshore Options}

On a Friday evening in July 2012, a mechanical fault caused a fire that totally destroyed Interface's carpet manufacturing plant in Picton on the southern outskirts of Sydney. At this point a realistic option was to wait for a likely insurance payout, expand the two operational manufacturing sites in the Asian region (in Thailand and China), and pull out of production in Australia to remain only as an importer of carpet tiles. This did not happen. On the Monday morning after the fire, the company announced to the 180 workers employed at the plant that it would guarantee the wages of all permanent employees for least 12 months while the company went through "a process of discovery of exactly what we're going to do" (Managing Director, Australia and New Zealand). One of the senior executives described 
how when the announcement was made "We didn't know. We had an intention of building but we didn't know whether we would rebuild or not" (Vice President Operations, AsiaPacific).

While a new site was found, employees were enrolled in helping with design of the new setup; production workers moved temporarily into customer service; and others did community projects in and around Picton all on full pay. All were assured continuing roles in the business.

The decision to rebuild could be construed as a purely financial decision to reestablish an operation that was "not only the [company's] best market share but by far the most profitable" (Managing Director, Australia and Zealand). However, we also see that more was at work in the decision and that an ethic of care for people and the ethos of the company came into play. In reflecting on the decision, the Vice President Operations, Asia-Pacific described how it was important to "go in a way which fitted with Ray's idea about who we were, and what we were about." This meant being "a heartbeat from the customer" so they could customize their "high design" product for customers and do so with short lead times. It meant valuing their existing workforce and retaining "the skills of our people because carpet manufacturing or textile skills are very thin on the ground in Australia these days" (Managing Director, Australia and Zealand).

An unexpected disaster is the kind of contingency that would push many companies toward a mainstream business as usual response. But in a company such as Interface, where the eye is on the long term, obstacles are opportunities to grow and get ahead of the game in new ways. Contingency, in this case, provoked care for production in place; at the same time, it gave rise to a major but unplanned upgrading of technical capacity. Continued manufacturing in Australia was validated, not as a localist stand, but because it allowed for a new articulation of nationally and globally sourced inputs into sustainable production.

\section{Family Ownership as a Bulwark against Financialization}

In the lead up to the GFC, corporate raiding and predatory asset stripping were rife in the endangered engineering sector in Australia. "Superannuation funds [were] looking for a quick dollar" and engineering firms "sign[ed] up all these contracts, real cheap, to try and make the business look good to sell, and then the business starts to run out of cash and fails" (General Manager, Specialized Vehicles, Varley Group). The Varley Group was about to succumb to the market pressures that were sending other similar businesses down; the workforce had contracted to sixty employees, and the bank had taken over its administration.

As a private firm that was family owned, however, Varley was able to withstand the financial pressures affecting other companies. The new Managing Director who took over in the late 1990s, just as the business was nearing collapse, felt the full weight of Varley's one hundred years of history on his shoulders. He was faced with a stark dilemma "to save the business rather than let it die which was the most likely event if no action was going to be taken." As the first nonfamily member of the company to assume control, he professionalized the business governance and scaled back the enterprise scope. He devised his own method of 
accounting in order to understand how the business worked and began to focus on expanding key areas where there was the potential for growth.

At a time when many competitors took on unrealistic contract work to look attractive to investors, Varley focused on providing quality engineering solutions across their key business units. As their competitors failed, Varley acquired their assets. As the Managing Director notes, he was not "worried about what my share price is reading at the moment" or "about what some analyst is predicting is going to happen to us in the future" or "being told by other people out there that our overheard ratio is too heavy for this or I'm not returning enough or I shouldn't be investing in this or that." Today Varley has a workforce of six hundred, many in regional Australia where it is preserving and nourishing manufacturing know-how.

Family-owned national manufacturers comprise a subset of nonpublically listed privately owned companies that have been largely unexamined in Australia. Yet these companies display business dynamics that are at odds with the business as usual model. As the Varley Group shows, commitment to a longer intergenerational time frame affects the way they do business differently and cannot be underestimated as a contributor to producing just sustainability.

\section{Cooperativism in the Face of Global Competition}

At the end of the 1990s and under the influence of neoliberal governance models, price controls that had effectively protected the dairy industry in Australia from global competition were in the process of being rolled back (Pritchard 1998). At this time, deregulation of the Australian food industry saw increased mergers and takeovers, and the demutualization of agricultural producer cooperatives was squarely on the agenda. Many aging farmer members of long-standing dairy producer cooperatives, especially those in the southern state of Victoria, were attracted by the significant (at least in the short term) financial benefits to be reaped (Cocklin and Dibden 2002).

Producer cooperatives are democratically run member-owned organizations whose farmer base elect representatives to the Co-op Board and employ a CEO to run the business. As in any democratically run organization, the challenge is to continue to align the cooperative values of serving the members' needs for a stable livelihood, with company strategies for survival in a cut throat global market for milk. In the late 1990s on the NSW north coast, Norco's CEO and half of the Board were tempted by the prospect of demutualization. According to the current Chairman and CEO, the then Chairman "wasn't overly co-op minded." For him "it was more about, how do we actually get this beast to a listing and actually get rid out of all the farmer directors and move away from the cultural issues of the co-operative?"

But others, like the current Chairman and CEO, wanted to stay true to the local farmer member base and the ethos of cooperation that had continued to bring them together over the one hundred-plus-year history of the enterprise. The critical question was how to survive deregulation and globalization as a cooperative. Under the guidance of the current Chairman and CEO, Norco strategically entered into partnerships with the largest industry players on 
the planet to keep afloat. This meant working with the multinational milk marketer Parmalat, and Fonterra, the NZ dairy multinational that is a cooperative in name only. The expectation was that they would be absorbed. But in both cases Norco was able, at a later date, to strategically and lucratively withdraw and rekindle allegiance to cooperative values. As a Research and Development Officer commented, "so whereas I thought the only thing that drives farmers is say profit, well it's not, it's lifestyle, it's the family, it's workload. There's so many other things, it's ethics."

Safeguarding cooperative values has meant strategic investment in expanding Norco's ice-cream manufacturing factory in Lismore so that it acts as a key stabilizer of company income, continuing to produce throughout the year using stored inputs that smooth out the seasonal fluctuations in milk sales. Today Norco has close to $\$ 600$ million in sales per annum and pays farmers the highest gate prices for raw milk. In Australia's globally competitive food processing sector, Norco has held its own and has demonstrated that financial pressures can be balanced with an ethos of care for people in place. As the Chairman put it, "Globalization has served its purpose and made us all aware that we need to change and move forward, but it doesn't mean that we need to abandon our own."

\section{Negotiating Justly Sustainable Growth}

Waste recycling is a rapidly growing industry in Australia with the consequence that, as the National Manager of Soft Landing admits, "The waste industry is cut throat." As with any growing market, new entrants are continually entering the sector and crowding out existing players. In such a dynamic context, social enterprises, not known for quick and decisive action, are at some disadvantage.

In the mid-2010s, an Australian-based for-profit multinational that used a fully automated mattress shredder was about to become a competitor in Soft Landing's most crucial mattress collection and recycling market in Sydney. The multinational was interested in acquiring Soft Landing, just as the social enterprise was seeking to grow nationally but was having troubles getting support from Mission Australia the charity under whose umbrella it had originally grown.

In a rather uncharacteristic set of moves Soft Landing played the cut throat landscape by fully embracing growth themselves. With their eyes firmly set on their social purpose, the management of Soft Landing negotiated a takeover by Resource Recovery Australia (RRA), another social enterprise with a shared ethos to care for people at a distance from the workforce. Soft Landing and RRA forged a cooperative relationship with the for-profit multinational so that the jobs created by Soft Landing were protected and over time could potentially even be increased, as the then National Manager explained: "[it's] a partnership: we'll be the front face, we'll do the collection, we'll be the social enterprise, we deliver to you the volume of mats that can go through your machine and you push the button on and the widgets and whatever go. Great, we'll keep some mats aside for our guys that are existing. We want a net gain in jobs, so we don't want to lose any jobs, we want more jobs." The most recent development is that Soft Landing has now taken over the multinational's mattress 
recycling operations and runs both the manual and the automated mattress shedding processes.

Here we have an unprecedented case of corporate takeover of a capitalist firm by a noncapitalist social enterprise, albeit supported by pro bono assistance from a major legal firm and underwritten by a grant from a corporate foundation. Today Soft Landing acts as a key negotiator in an industry-led voluntary mattress stewardship program in which the entire mattress sector cooperates to ensure end-of-life recycling of as many mattresses as possible across Australia. This company is prototyping a new kind of business model, one in which direct commitments to planetary and human survival play a decisive role.

These four small stories offer glimmers of new cultures of production in Australia in which the license to exist is linked to caring for just sustainability. All of these businesses are financially viable, but they are redefining what business viability now means. As a Senior Executive of Interface Europe put it,

People think okay, now it's circular economy and then they might forget about lowcarbon economy and they might forget about bio-based economy and they might forget inclusive economy ... Okay, you can discuss about the order, whatever, but it's and, and, and - that's the whole point. Only when a company can contribute to all those elements, [do] I think you have this licence to exist.

\section{Conclusion}

In a world where the next generation of business leaders see the business as usual model as the major barrier to challenging climate change and global inequality, it seems that theorizing possibility is much needed. There is an important role for economic geographers here. We cannot be indifferent to the obvious problem of manufacturing in the age of the Anthropocene. Our choice in the minority world is to insulate ourselves against the damageto go on with a few human and nonhuman kin over time, to pin our hopes on technological solutions, to build bigger walls, dim the lights and pretend like no one is home when the stranger comes - or we can make such repairs as we are capable of making, and along the way we can attempt to solve problems, and engage with and nourish one another.

Roepke asked in 1977 "Should we, must we, can we?" do applied geography that advocates solutions to bold problems. This article has proposed that economic geography in the Anthropocene should not shy away from the obvious problems of dangerous climate change and increasingly unjust socioeconomic inequality. So our answer to Roepke must be a resounding yes, yes and yes. We must intervene and bring to light pathways that will steward our earth system along a more benign trajectory. We might also take heed of Reopke's warning that "[t]imidity or obscurity in reporting results, rather than lack of relevance ... has hampered recognition of the utility of geography" (1977, 481-82).

Geographic research has always operated in the critical zone where, as Latour puts it, the most pressing problems of our age can be parsed, and where the actions of humans can be radically reshaped to compose our common world differently. In this article we have thrown timidity to the winds to argue that the glimmers of a new culture of manufacturing that cares for just sustainability are to be seen. Our focus has been squarely on manufacturing in 
Australia, and thus geography matters in what we have identified. Some of these geographic dimensions include proximity to Asia and distance from northern markets; first and second generation overseas migrants comprising half of the population; a White Australia policy, which was only abandoned in 1973; a strong history of unionization; the absence of an uberrich industrial capitalist class; the near genocide of Aboriginal Australians by white European settlers; daily evident climate change effects; and land degradation linked to industrial agriculture. These geographic specificities overdetermine how manufacturing happens and how just sustainability can be developed. In the on-site workshops with enterprises in our research project, participants have been interested to see their collective actions and experiments presented back as forms of care for people and care for the planet. The language of just sustainability has been appreciated as a new way of portraying what they are doing. Our research intervention thus far has tested out this new language to see how it sits with people more used to talking about production outputs and market share. Whether this language can be employed in other settings with different geographies is a matter for further exploration.

For us, research has performative effects, thus it is always interventionist. To represent manufacturing via the language of just sustainability is one step toward making regenerative and caring ethical economies more real, at least in Australia. To identify how manufacturing is a form of collective action that can enact care for people and the planet and retain business viability is to usher in a new model of ethical enterprise. In the course of our research conversations we are shaping ourselves and our participants as experimental subjects capable of care for the complex life-sustaining web we inhabit.

\section{References}

Agyeman, J. 2013 Introducing just sustainability: Policy, planning, and practice. London: Zed Books.

Agyeman, J., Bullard, R., and Evans, B., eds. 2003. Just sustainability: Development in an Unequal World. Cambridge, MA: MIT Press.

Beverland, M., Nielsen, B., Pryce, V., and Hellmann, E. 2015. Redesigning manufacturing: Reimagining the business of making in the UK. London: Palgrave McMillan.

Bluestone, B., and Harrison, B. 1982. The deindustrialization of America: Plant closings, community abandonment and the dismantling of basic industry. New York: Basic Books.

Cameron, J., and Gibson, K. 2005. Alternative pathways to community and economic development: The Latrobe Valley community partnering project. Geographical Research 43 (3): 274-85. doi: 10.1111/j.1745-5871.2005.00327.x.

Carr, C., and Gibson, C. 2016. Geographies of making: Rethinking materials and skills for volatile futures. Progress in Human Geography 40 (3): 297-315. doi: $10.1177 / 0309132515578775$.

Cassidy, J. 2014. Picketty's inequality story in six charts. New Yorker, March 26. https://www.newyorker.com/news/john-cassidy/pikettys-inequality-story-in-sixcharts. 
Cherrafi, A., Elfezazi, S., Chiarini, A., Mokhlis, A., and Benhida, K. 2016. The integration of lean manufacturing, Six Sigma and sustainability: A literature review and future research directions for developing a specific model. Journal of Cleaner Production 139: 828-46. doi: 10.1016/j.jclepro.2016.08.101.

Chiarini, A. 2014. Sustainable manufacturing-greening processes using specific Lean Production tools: An empirical observation from European motorcycle component manufacturers. Journal of Cleaner Production 85 : 226-33. doi: 10.1016/j.jclepro.2014.07.080.

Christopherson, S. 2015. How does financialization affect manufacturing investment? Preliminary evidence from the US and UK. In Handbook of manufacturing industries in the world economy, ed. J. R. Bryson, J. Clark, and V. Vanchan, 42-57. Cheltenham, UK: Edward Elgar.

Clark, J., Bryson, J. R., and Vanchan, V. 2015. Conclusion: Regeneration economies: Manufacturing as the next industrial revolution. In Handbook of manufacturing industries in the world economy, ed. J. R. Bryson, J. Clark, and V. Vanchan, 491-502. Cheltenham, UK: Edward Elgar.

Cocklin, C., and Dibden, J. 2002. Taking stock: Farmers' reflections on the deregulation of Australian dairying. Australian Geographer 33 (1): 29-42. doi: https://doi.org/10.1080/00049180220124999.

Commonwealth Scientific and Industrial Research Organisation. 2016. Advanced manufacturing: A roadmap for unlocking future growth opportunities for Australia. Sydney, Australia: Advanced Manufacturing Growth Centre.

Community Economies Collective. 2001. Imagining and enacting non-capitalist futures. Socialist Review 28 (3/4): 93-135.

Copjec, J. 2006. May 68: An emotional month. In Lacan: The silent partners, ed. S. Žižek, 90-114. London: Verso.

Dicken, P. 2015. Global shift: Mapping the contours of the changing world. 7th ed. New York: Sage Publications.

Gibson, K. 1980. Internationalisation of capital and uneven development within capitalist countries. In An introduction to Marxist theories of underdevelopment, ed. R. Peet, 169-73. Canberra, Australia: ANU Press.

Gibson, K., Cahill, A., and McKay, D. 2010. Rethinking the dynamics of rural transformation: Performing different development pathways in a Philippine municipality. Transactions of the Institute of British Geographers 35 (2): 237-55. doi: 10.1111/j.1475-5661.2009.00378.x.

Gibson, K., Graham, J., and Shakow, D. 1989. Calculating economic indicators in value terms for the Australian economy and for individual industrial sectors, 1974-75 and 1978-79: Method and findings. Journal of Australian Political Economy 25 (October): 45-73.

Gibson, K., Graham, J., Shakow, D., and Ross, R. 1984. A theoretical approach to capital and labour restructuring. In Regional restructuring under advanced capitalism, ed. P. O'Keefe, 39-64. Sydney, Australia: Croom Helm.

Gibson, K., and Horvath, R. 1983a. Global capital and the restructuring crisis in Australian manufacturing. Economic Geography 59 (2): 178-94. . 1983b. Aspects of a theory of transition within the capitalist mode of production. Environment and Planning D: Society and Space 1 (2): 121-38. doi: 10.1068/d010121. 
Gibson-Graham, J. K. 1996. The end of capitalism (as we knew it): A feminist critique of political economy. Minneapolis: University of Minnesota Press. .2006. A postcapitalist politics. Minneapolis: University of Minnesota Press. 2008. Diverse economies: Performative practices for 'other worlds'. Progress in Human Geography 32 (5): 613-32. doi: 0.1177/0309132508090821.

Gibson-Graham, J. K., Cameron, J., and Healy, S. 2013. Take back the economy: An ethical guide for transforming our communities. Minneapolis: University of Minnesota Press.

Graham, J., Gibson, K., Horvath, R., and Shakow, D. 1988. Restructuring of U.S. manufacturing: The decline of monopoly capitalism. Annals of the Association of American Geographers 78 (3): 473-90. doi: 10.1111/j.1467-8306.1988.tb00219.x.

Goennemman, J. 2016. Forward. In Sector competitiveness plan 2017: Taking Australian ingenuity to the world. Sydney, Australia: Advanced Manufacturing Growth Centre.

Haraway, D. 2015. Anthropocene, capitalocene, plantationocene, chthulucene: Making kin. Environmental Humanities 6 (1): 159-65. doi: https://read.dukeupress.edu/environmental-humanities/articlepdf/6/1/159/251848/159Haraway.pdf.

Harvey, D. 1973. Social justice and the city. Baltimore: Johns Hopkins University Press. Hawken, P. 2010. The ecology of commerce. Rev. ed. New York: Harper Business.

Healy, S. 2015. Biofuels, ex-felons, and Empower, a worker-owned cooperative: Performing enterprises differently. In Making other worlds possible: Performing diverse economies, ed. G. Roelvink, K. St. Martin, and J. K. Gibson-Graham, 98-127. Minneapolis: University of Minnesota Press.

Helper, S., Krueger, T. and Wial, H. 2012. Why does manufacturing matter? Which manufacturing matters? A policy framework. Washington D.C.: Brookings Institute.

Herod, A. 2001. Labor geographies: Workers and the landscapes of capitalism. New York: Guilford Press.

Industry Canada. 2015. Strengthening Canada's manufacturing sector. Ottawa, Canada: Industry Canada.

Inman, R. A., and Green, K. W. 2018. Lean and green combine to impact environmental and operational performance. International Journal of Production Research 56 (14): 4802-18. doi: 10.1080/00207543.2018.144770.

Interface. 2012. Fotosfera. Interface. https://download.architonic.com/pdf/310/1272/interfacefotosfera-en.pdf.

Latour, B. 2004. Why has critique run out of steam? From matters of fact to matters of concern. Critical Inquiry 30 (Winter): 225-48. doi: 10.1086/421123. . 2014. Some advantages of the notion of "critical zone" for geopolitics. Procedia Earth and Planetary Science 10: 3-6. doi:10.1016/j.proeps.2014.08.002.

Lawson, V. 2007. Geographies of care and responsibility. Annals of the Association of American Geographers 97 (1): 1-11. doi: 10.1111/j.1467-8306.2007.00520.x.

Marx, K. [1867] 1992. Capital, Vol. 1: A Critical analysis of capitalist production, trans. B. Fowkes. New York: Penguin Classics.

Massey, D. 1984. Spatial divisions of labour. London: Macmillan.

Massey, D., and Meegan, R. 1982. The anatomy of job loss. London: Methuen.

National Research Council. 2001. Basic research opportunities in earth science. Washington, DC: National Academies Press. 
Nelson, E. 2009. How Interface innovates with suppliers to create sustainable solutions. Global Business and Organizational Excellence 28 (6): 22-30. doi: 10.1002/joe.202.

Pritchard, W. N. 1998. The emerging contours of the third food regime: Evidence from Australian dairy and wheat sectors. Economic Geography 74 (1): 64-74. doi: https://doi.org/10.1111/j.1944-8287.1998.tb00105.x.

Puig de la Bellacasa, M. 2017. Matters of care: Speculative ethics in more than human worlds. Minneapolis: University of Minnesota Press.

Roepke, H. G. 1977. Applied geography: Should we, must we, can we? Geographical Review 67 (4): 481-82.

Schoenberger, E. 2000. The management of time and space. In The Oxford handbook of economic geography, ed. G. L. Clark, M. Feldman, and M. S. Gertler, 317-32. Oxford,: Oxford University Press.

Scott, A. 1987. The semi-conductor industry in Southeast Asia: Organization, location, and the international division of labour. London: Allen and Unwin.

Stanford, J., and Swann, T. 2017. Manufacturing: A moment of opportunity. Briefing paper for the National Manufacturing Summit. Canberra, Australia: Centre for Future Work at the Australia Institute.

Steffen, W., Broadgate, W., Deutsch, L., Gaffney, O., and Ludwig, C. 2015. The trajectory of the Anthropocene: The great acceleration. The Anthropocene Review 2 (1): 81-98. doi: $10.1177 / 2053019614564785$.

St. Martin, K. 2001. Making space for community resource management in fisheries. Annals of the Association of American Geographers 91 (1): 122-42. doi: 10.1111/00045608.00236.

Technology Strategy Board. 2012. A landscape for the future of high value manufacturing in the UK. Swindon, UK: Technology Strategy Board.

Tronto, J., and Fisher, B. 1990. Toward a feminist theory of caring. In Circles of care: Work and identity in women's lives, ed. E. K. Abel and M. K. Nelson, 35-62. Albany: State University of New York Press.

Vanchan, V., Bryson, J.R., and Clark, J. 2015. Introduction: Manufacturing matters: Space, place, time and production. In Handbook of manufacturing industries in the world economy, ed. J. R. Bryson, J. Clark, and V. Vanchan, 3-16. Cheltenham, UK: Edward Elgar.

Waters, C., Zalasiewicz, J., Summerhayes, C., Barnosky, A., Poirier, C., Galuszka, A., Cearreta, A., Edgeworth, M., Ellis, E., Ellis, M., Jeandel, C., Leinfelder, R., McNeill, J., Richter, D., Steffen, W., Syvitski, J., Vidas, D., Wagreich, M., Williams, M., Zhisheng, A., Grinevald, J., Odada, E., Oreskes, N. and Wolfe, A. 2016. The Anthropocene is functionally and stratigraphically distinct from the Holocene. Science 351 (6269): 137-47. doi: 10.1126/science.aad2622.

Woo, E. 2011. Mogul made his firm model green business. LA Times, August 15. http://articles.latimes.com/2011/aug/15/local/la-me-ray-anderson-20110815. 